\title{
Bioavailability of Iron to Pseudomonas fluorescens Strain A506 on Flowers of Pear and Apple
}

\author{
Todd N. Temple, Virginia O. Stockwell, Joyce E. Loper, and Kenneth B. Johnson
}

First to fourth authors: Department of Botany and Plant Pathology, Oregon State University, Corvallis 97330; and third author: U.S. Department of Agriculture-Agricultural Research Service, Horticultural Crops Research Laboratory, 3420 NW Orchard Avenue, Corvallis 97330.

Accepted for publication 16 August 2004.

\begin{abstract}
Temple, T. N., Stockwell, V. O., Loper, J. E., and Johnson, K. B. 2004. Bioavailability of iron to Pseudomonas fluorescens strain A506 on flowers of pear and apple. Phytopathology 94:1286-1294.

The addition of $0.1 \mathrm{mM} \mathrm{FeCl}_{3}$ to a defined culture medium induces the bacterial epiphyte Pseudomonas fluorescens strain A506 (A506) to produce an antibiotic toxic to the fire blight pathogen, Erwinia amylovora. Consequently, because A506 is registered and applied as a commercial product to suppress E. amylovora before floral infection of pear and apple, the relative availability of iron to A506 on surfaces of pear and apple flowers is of potential significance. An 'iron biosensor' construct of A506 was developed by transformation with an iron-regulated promoter $(p v d)$ fused to a promoterless ice nucleation reporter gene (inaZ). This construct, A506 ( $p v d$-inaZ), established high populations on pear and apple flowers, ranging from $10^{4}$ to $10^{6} \mathrm{CFU} /$ flower. In seven trials on pear and

apple trees, A506 ( $p v d$-inaZ) expressed high ice nucleation activity (INA) on flowers, indicating limited iron bioavailability or a low-iron environment unlikely to induce antibiotic production by A506. A506 ( $p v d$-inaZ) also colonized flowers when mixed with chemicals containing iron: $\mathrm{FeSO}_{4}$ or the iron chelates ferric ethylenediaminedi-(o-hydroxyphenylacetic) acid (FeEDDHA) and ferric diethylenetriamine pentaacetate (FeDTPA). These compounds represent an array of commercial iron formulations applied to foliage to avert iron chlorosis. Treatment of flowers with a mixture of A506 ( $p v d$-inaZ) and $3 \mathrm{mM}$ FeEDDHA or FeDTPA significantly decreased INA compared with flowers treated with A506 (pvd-inaZ) in water. Lower concentrations $(0.3 \mathrm{mM})$ of FeEDDHA, however, did not consistently suppress INA. These results indicate that apple and pear flowers represent an iron-limited environment to A506 and that treatment with $3 \mathrm{mM}$ FeEDDHA is needed to increase significantly the level of iron available to this bacterium.
\end{abstract}

Pseudomonas fluorescens strain A506 (A506) is a commercially available biological control agent (BlightBan A506; Nufarm Americas Inc., Sugar Land, TX) used for the suppression of fire blight on pear and apple trees. Effective biocontrol with A506 requires that the bacterium preemptively colonize and establish large populations on flower surfaces prior to colonization by the fire blight pathogen, Erwinia amylovora $(6,10,24,26,30)$. Disease suppression by A506 has been proposed to occur by the mechanism of "competitive exclusion," whereby A506 outcompetes E. amylovora for sites and nutrients essential for epiphytic growth and subsequent infection of the host plant $(27,29,30)$.

Recently, Stockwell et al. (25) observed that A506 produced a large zone of inhibition to E. amylovora when cultured on defined media amended with $0.1 \mathrm{mM} \mathrm{FeCl}$. Because the zone of inhibition on iron-amended media is indicative of antibiotic production, questions arise with regard to the potential significance of antibiosis in the biocontrol interaction and the relative bioavailability of iron to A506 in the microhabitats located on surfaces of pear and apple flowers. If sufficient iron is available to A506 in situ, production of the antibiotic may occur, suggesting that this strain may utilize an additional mechanism to attain an epiphytic advantage over E. amylovora. Conversely, if little iron is available on floral surfaces, competitive exclusion may be the principal mechanism of suppression, raising the question as to whether biocontrol can be enhanced by the addition of an exogenous source of iron to the flower environment.

Corresponding author: V. O. Stockwell

E-mail address: stockwev@science.oregonstate.edu

Publication no. P-2004-1011-01R

(C) 2004 The American Phytopathological Society
Iron is the fourth most abundant element on earth; however, at neutral or basic $\mathrm{pH}$ in aerated environments, it exists principally as insoluble iron oxides $(12,23)$. Prior studies $(7,15)$ have demonstrated that the amount of bioavailable iron on aerial plant surfaces can be limiting to microbes. In response, bacteria that reside on plant surfaces produce iron-sequestering compounds called siderophores $(1,20,22,23)$. Fluorescent pseudomonads produce pyoverdines, which are distinct yellow-green, water-soluble, low molecular weight siderophores (1). Typically, pyoverdine is produced and secreted into the environment when iron bioavailability is low and its production is suppressed when iron is abundant (22,23).

Phyllosphere environments are relatively uncharacterized with regard to the bioavailability of nutrients to microbial epiphytes. For iron specifically, Loper and Lindow (15) determined that this nutrient was limiting, at least partially, to epiphytic populations of $P$. syringae on bean leaf surfaces. Subsequently, Joyner and Lindow (7) reported that iron bioavailability to $P$. syringae was heterogeneous on leaves and that only $10 \%$ of bacterial cells experienced iron-limiting conditions. Floral surfaces as microbial habitats are less characterized than leaves. We recognize that stigmatic surfaces of pear and apple flowers provide a protected, nutrient-rich, hydrated environment, which bacteria exploit and where they amass large populations (5). The diversity and relative abundance of nutrients such as iron that support microbial growth on stigmas is not known.

For Pseudomonas spp., a reporter gene for iron bioavailability has been developed that consists of a transcriptional fusion between the iron-regulated promoter of a pyoverdine biosynthesis and uptake region ( $p v d$, from $P$. syringae) and a promoterless ice nucleation gene (inaZ, also from $P$. syringae) $(15,16)$. The inaZ gene product is an outer-membrane protein (InaZ) that catalyzes 
(nucleates) the formation of ice when suspended in supercooled water at temperatures ranging from -2 to $-10^{\circ} \mathrm{C}(11)$; in the absence of ice nuclei, water can supercool to temperatures approaching $-40^{\circ} \mathrm{C}$ before freezing $(11,15,16)$. The transcriptional activity of the reporter gene is quantified after establishment of the host bacterium in the environment of interest (16). Abundant bioavailable iron results in low ice nucleation activity (INA) (i.e., the frequency of ice nuclei per CFU), whereas limited bioavailable iron results in high INA $(13,15,16,18)$.

The purpose of this study was to estimate the relative availability of iron to $P$. fluorescens strain A506 on pistillate surfaces of pear and apple flowers by using an iron biosensor construct of this bacterium. Moreover, exogenous sources of iron were applied to flowers along with the iron biosensor construct of A506 to determine if they enhance bioavailable iron in the microhabitats occupied by the bacterium on floral surfaces.

\section{MATERIALS AND METHODS}

Bacterial strains and plasmids. The bacterium $P$. fluorescens strain A506 was used in all experiments. It was first isolated from a pear leaf in California by S. Lindow (University of California, Berkeley), and is resistant to streptomycin and rifampicin (10). Constructs of A506 included (i) the biosensor strain, A506 ( $p v d$ inaZ), which contained an iron-regulated promoter for pyoverdine production ( $p v d$ ) fused to promoterless inaZ (15); (ii) A506 IceC, a positive control strain where $i n a Z$ is transcribed constitutively from its native iron-independent promoter; and (iii) A506 Ice ${ }^{-}$, a negative control strain consisting of promoterless inaZ cloned in opposite orientation to the lac promoter in the cloning vector, plasmid VSP61a (such that inaZ is not transcribed). pVSP61a was the cloning vector for all constructs; this stable plasmid was used originally in P. syringae (15) and confers resistance to kanamycin (15). The iron biosensor and the control constructs have been used in P. putida strain N1R and P. fluorescens strain Pf-5 $(13,15)$.

Effects of iron on pyoverdine production and antibiosis by A506 in culture. The relationship of iron concentration to pyoverdine production and antibiosis by A506 was evaluated on solidified 925 minimal medium with $1.5 \%$ potassium gluconate as the carbon source (8). A 15- $\mu$ l suspension of A506 was spotted onto petri dishes containing solidified 925 medium amended with ferric citrate at concentrations ranging from 0.001 to $1 \mathrm{mM}$. After $72 \mathrm{~h}$ of incubation at $20^{\circ} \mathrm{C}$, plates were examined visually for the characteristic yellow-green fluorescence associated with pyoverdine under long wavelength (404 nm) UV irradiation. A506 was removed from the agar surface with a cotton swab and the remaining cells were killed by exposure to chloroform vapor or a germicidal UV lamp. Plates were lightly sprayed with a $10^{7} \mathrm{CFU} / \mathrm{ml}$ aqueous suspension of E. amylovora strain Ea153 (Ea153) (6). After 48 to $72 \mathrm{~h}$, plates were examined for the presence of zones inhibitory to the growth of Ea153.

Semi-quantitative methods to measure pyoverdine and antibiosis were used for broth cultures of A506. In broth cultures, A506 was grown at $20^{\circ} \mathrm{C}$ with agitation $(200 \mathrm{rpm})$ in triplicate $5-\mathrm{ml}$ volumes of both 925 medium and modified RSM (2). For 1 liter of modified RSM medium, $0.75 \mathrm{~g}$ of $\mathrm{Ca}\left(\mathrm{NO}_{3}\right)_{2} \cdot 4 \mathrm{H}_{2} \mathrm{O}, 0.25 \mathrm{~g}$ of $\mathrm{MgSO}_{4} \cdot 7 \mathrm{H}_{2} \mathrm{O}, 18.22 \mathrm{~g}$ of ACES [ $\mathrm{N}$-(2-acetamido)-2-aminoethanesulfonic acid], and $2.00 \mathrm{~g}$ of $\mathrm{NaOH}$ were dissolved in $879 \mathrm{ml}$ of deionized water, and the $\mathrm{pH}$ was adjusted to 7.0. After autoclaving, $1 \mathrm{ml}$ of $1 \mathrm{M} \mathrm{KH}_{2} \mathrm{PO}_{4}(\mathrm{pH} \mathrm{7.0)}, 20 \mathrm{ml}$ of $50 \%$ (vol/vol) glycerol, and $100 \mathrm{ml}$ of $10 \%$ (wt/vol) Casamino acids were added. RSM has been used previously for evaluation of ironregulated transcription of $p v d$-ina $Z$ and for pyoverdine production by pseudomonads (15); however, the antibiotic of A506 cannot be detected by bioassay in RSM. Ferric citrate was added to 925 medium or RSM to final concentrations ranging from 0.001 to $1 \mathrm{mM}$. After 48 and $72 \mathrm{~h}$ of incubation, the absorbance at $600 \mathrm{~nm}$ $\left(A_{600}\right)$ of cultures was measured to estimate cell density. To esti- mate pyoverdine concentration, cells were removed from a 1-ml broth culture sample by centrifugation $(5 \mathrm{~min}, 2,500 \times \mathrm{g})$ and $\mathrm{FeCl}_{3}$ was added to the supernatant to a final concentration of $1 \mathrm{mM}$. After gentle agitation for $30 \mathrm{~min}$, samples were centrifuged for $5 \mathrm{~min}$ to remove precipitates. $A_{405}$ of the clarified supernatant was measured with an Ultrospec 3100 Pro (Amersham Biosciences Corp., Piscataway, NJ). Pyoverdine production was calculated by dividing the ferric-pyoverdine complex $A_{405}$ value by the cell density $\mathrm{A}_{600}$ value (15).

Relative antibiotic production, measured with a dilution endpoint method, was determined for the 72-h broth cultures in 925 medium. As above, cells were removed from cultures by centrifugation and the supernatant was sterilized by filtration $(0.2 \mu \mathrm{m})$. For each culture, $200 \mu \mathrm{l}$ of culture filtrate, serial dilutions $(1: 2$, $1: 4,1: 8,1: 16,1: 32$, and 1:64) of the filtrate made with $10 \mathrm{mM}$ potassium phosphate buffer, $\mathrm{pH} 7.0$, or phosphate buffer alone were placed into individual wells of a 96-well Falcon microtest plate (Becton-Dickinson Labware, Franklin Lakes, NJ). A 20- $\mu$ l sample of a $10^{6} \mathrm{CFU} / \mathrm{ml}$ suspension of Ea153 was added to each well of the microtiter plate. After $24 \mathrm{~h}$ of incubation at room temperature, a 8.5- $\mu$ l sample was removed from each well and placed on solidified 925 medium amended with $1.5 \%$ potassium gluconate, $0.1 \mu \mathrm{M}$ thiamine, and $0.1 \mu \mathrm{M}$ nicotinic acid. Plates were air dried in a laminar airflow hood until the visible liquid was absorbed and then incubated at $20^{\circ} \mathrm{C}$ for 3 days. Plates were observed for the greatest dilution of culture filtrate that inhibited growth of Ea153 compared with the control, and a relative antibiosis value was assigned to the endpoint dilution (e.g., if growth of Ea153 was inhibited with 1:16 dilution of the culture filtrate, but not 1:32, then the sample was assigned the relative antibiosis value of 16). All experiments conducted with solidified and broth media were repeated once.

Transcriptional activity of $p v d$-inaZ in culture. The effect of iron on INA expression by P. fluorescens A506 (pvd-inaZ) and $P$. putida N1R containing pvd-inaZ was evaluated in 5-ml broth cultures of modified RSM medium (described above) in 15-mm test tubes. The medium was supplemented with ferric citrate or a chelated form of iron ferric ethylenediaminedi-(o-hydroxyphenylacetic (FeEDDHA) acid (Sequestrene 138; Becker Underwood, Ames, IA) to final concentrations ranging from 1 to $0.001 \mathrm{mM}$. Bacterial strains from overnight broth cultures were added to broth at a concentration of $\approx 1 \times 10^{6} \mathrm{CFU} / \mathrm{ml}$. After $24 \mathrm{~h}$ at $20^{\circ} \mathrm{C}$ on a rotary shaker $(200 \mathrm{rpm})$, samples were evaluated for INA with the droplet freezing assay (described below) and for CFU by dilution plating on Pseudomonas agar F (PAF) medium (Difco Laboratories, Detroit, MI) amended with kanamycin at $50 \mu \mathrm{g} / \mathrm{ml}$. Reported values are the means of three replicate cultures. The results from duplicate experiments were similar, and results of a representative experiment are presented.

Screenhouse experiment. Seven experiments to measure INA in constructs of A506 applied to flowers of pear or apple cultivars were conducted during March to May 2001 to 2003 (Table 1). The pear and apple trees ranged from 5 to 10 years old, and were located in a screenhouse facility at the Oregon State University, Department of Botany and Plant Pathology Field Laboratory near Corvallis. Trees in the screenhouse were protected from rain and ultraviolet radiation by a translucent, fiberglass roof, and from insect visitations by 2-by-2-mm steel screen walls. Flowers of pear (Pyrus calleryana cv. Aristocrat in 2001 to 2003 experiments and $P$. communis cv. Bartlett in 2002 to 2003 experiments) and apple (Malus $\times$ domestica cv. Golden Delicious and crabapple Malus $\times$ Snowdrift in 2001 experiments) were spray inoculated with aqueous suspensions of A506 ( $p v d$-inaZ), A506 Ice $\mathrm{Ice}^{-}$or A506 IceC. Constructs of A506 were cultured for 2 to 4 days at $27^{\circ} \mathrm{C}$ on nutrient agar (Difco Laboratories) containing $0.4 \% \mathrm{wt} / \mathrm{vol}$ glycerol, $0.5 \% \mathrm{wt} / \mathrm{vol}$ sucrose, and $0.1 \mathrm{mM}$ ferric citrate. Ferric citrate was added to the medium to suppress INA in the inoculum. Bacteria were scraped from the surface of the medium and suspended 
in $10 \mathrm{mM}$ potassium phosphate buffer $(\mathrm{pH}$ 7.0). Bacterial suspensions were adjusted to $\approx 1 \times 10^{8} \mathrm{CFU} / \mathrm{ml}$ (optical density at $600 \mathrm{~nm} \approx 0.1$ ) with the aid of a spectrophotometer (Spectronic 20; Bausch and Lomb, Rochester, NY). All bacterial suspensions were sprayed to near runoff with hand-held trigger sprayers (800-ml capacity). In all experiments, each A506 construct was applied onto several flower clusters on a branch of a tree. Each set of construct inoculations was replicated on three trees per cultivar.

Iron treatments. Additional treatments involved inoculum of A506 ( $p v d$-inaZ) applied to flowers with commercial formulations of iron (Table 1). All seven experiments included A506 (pvd-inaZ) mixed at the time of inoculation with $3 \mathrm{mM}$ FeEDDHA (Sequestrene 138, 100\% FeEDDHA; Becker Underwood). This concentration of FeEDDHA $(1 \mathrm{lb}$. of Sequestrene 138 per 100 gallons of water) is the manufacturer's recommended rate of Sequestrene 138 for a foliar spray to alleviate iron chlorosis of pome fruit trees. A506 ( $p v d$-inaZ) also was combined with Sequestrene 138 at concentrations ranging from 30 to $0.03 \mathrm{mM}$. A control treatment in 2002 included A506 ( $p v d$-inaZ) mixed with $0.1 \mathrm{mM}$ EDDHA (no iron). We also evaluated a treatment where flowers were inoculated with A506 ( $p v d$-inaZ) in water and then oversprayed with $3 \mathrm{mM}$ FeEDDHA at $48 \mathrm{~h}$ after inoculation. Additional formulations of iron included as co-treatments with A506 ( $p v d$-inaZ) in several experiments were 0.1 and $18 \mathrm{mM}$ $\mathrm{FeSO}_{4}$ (Sigma-Aldrich, St. Louis), $2.7 \mathrm{mM}$ ferric diethylenetriamine pentaacetate (FeDTPA) (Sequestrene 330, 100\% FeDTPA; Becker Underwood), and $0.3 \%$ (vol/vol) metalosate iron $(5 \%$ [wt/vol] total iron as amino acid chelates; Albion Laboratories, Inc., Clearfield, UT) (Table 1). The concentrations represent the manufacturer's recommended rate as foliar sprays to alleviate iron chlorosis of tree crops.

Estimation of population size of $\mathbf{A 5 0 6}$ constructs. For each treatment, flowers were sampled three to four times during bloom to estimate population size of each construct of A506. Sample sizes were 10 flowers/treatment except for the Golden Delicious apple trial in 2001, where only 6 flowers were sampled. Sampled flowers were transported to the laboratory in individual wells of sterile, 24-well microtiter plates, and then processed individually for dilution plating. The pistil and hypanthium from pear flowers or pistils only from apple flowers were dissected using sterile forceps and sonicated (Sonix IV, Inglewood, CA) in $1 \mathrm{ml}$ of sterile $10 \mathrm{mM}$ potassium phosphate buffer $(\mathrm{pH}$ 7.0) for 3 min. After sonication and vortex mixing, a 10- $\mu$ l drop of the wash and two 100 -fold serial dilutions were spread onto PAF medium amended with rifampicin at $50 \mu \mathrm{g} / \mathrm{ml}$, kanamycin at $50 \mu \mathrm{g} / \mathrm{ml}$, and cycloheximide at $50 \mu \mathrm{g} / \mathrm{ml}$. The detection limit was $1 \times 10^{2} \mathrm{CFU} /$ flower. Colonies were counted after 3 days.

Ice nucleation assay. INA was determined in a most probable number, droplet-freezing assay (10). Forty 10- $\mu$ l drops from the flower wash and from appropriate dilutions were dispensed on aluminum foil boats covered with a thin layer of dried wax (SC Johnson paste wax, Racine, WI). The foil boats were floated on ethanol maintained at $-5^{\circ} \mathrm{C}(11,15)$. The number of drops that froze at each dilution was recorded.

Data analysis. For each treatment, CFU/flower and INA were estimated from the count data obtained in the dilution plating and freezing-droplet assays. Population size data were transformed to $\log _{10}$ (CFU/flower). Calculation of INA was based on the method presented by Vali (28), $N=V_{t} \cdot \ln \left[1 /\left(1-P_{f}\right)\right] / V_{d} \cdot D$, where $N$ is the concentration of ice nuclei per sample, $V_{t}$ and $V_{d}$ represent volumes of the dilution tube and the droplet, respectively, $D$ is the serial dilution $\left(10^{0}, 10^{-1}, 10^{-2}, 10^{-3}, 10^{-4}\right.$, or $\left.10^{-5}\right)$, and $P_{f}$ is the proportion of frozen drops at the selected dilution. The INA was calculated by dividing $N$ by the CFU/flower and transforming to $\log _{10}(\mathrm{~N} / \mathrm{CFU})$.

For each treatment, the mean $\log _{10}$ (CFU/flower) and INA (mean $\log _{10}$ [ice nuclei/CFU]) were plotted as a function of hours after inoculation. For individual sampling dates, analysis of variance (ANOVA) was conducted to test equality of means among constructs of A506 inoculated in water and, separately, among rates of iron co-treatments applied with A506 ( $p v d$-inaZ) (PROC GLM, Statistical Analysis System; SAS Institute, Cary, NC). Similarly, within a replicate, average population size or INA for a construct or treatment was calculated for all samples taken from 24 to $120 \mathrm{~h}$ after inoculation, and these averages were subjected to ANOVA. Fischer's protected least significant difference $(P \leq$ 0.05 ) was used to evaluate differences among means.

\section{RESULTS}

Effect of iron concentration on pyoverdine production and antibiosis by $\mathbf{A 5 0 6}$ in culture. On solidified 925 medium containing $0.001 \mathrm{mM}$ ferric citrate, A506 was highly fluorescent when exposed to long UV and did not exhibit antibiosis against

TABLE 1. Cultivar, inoculation date, and treatments

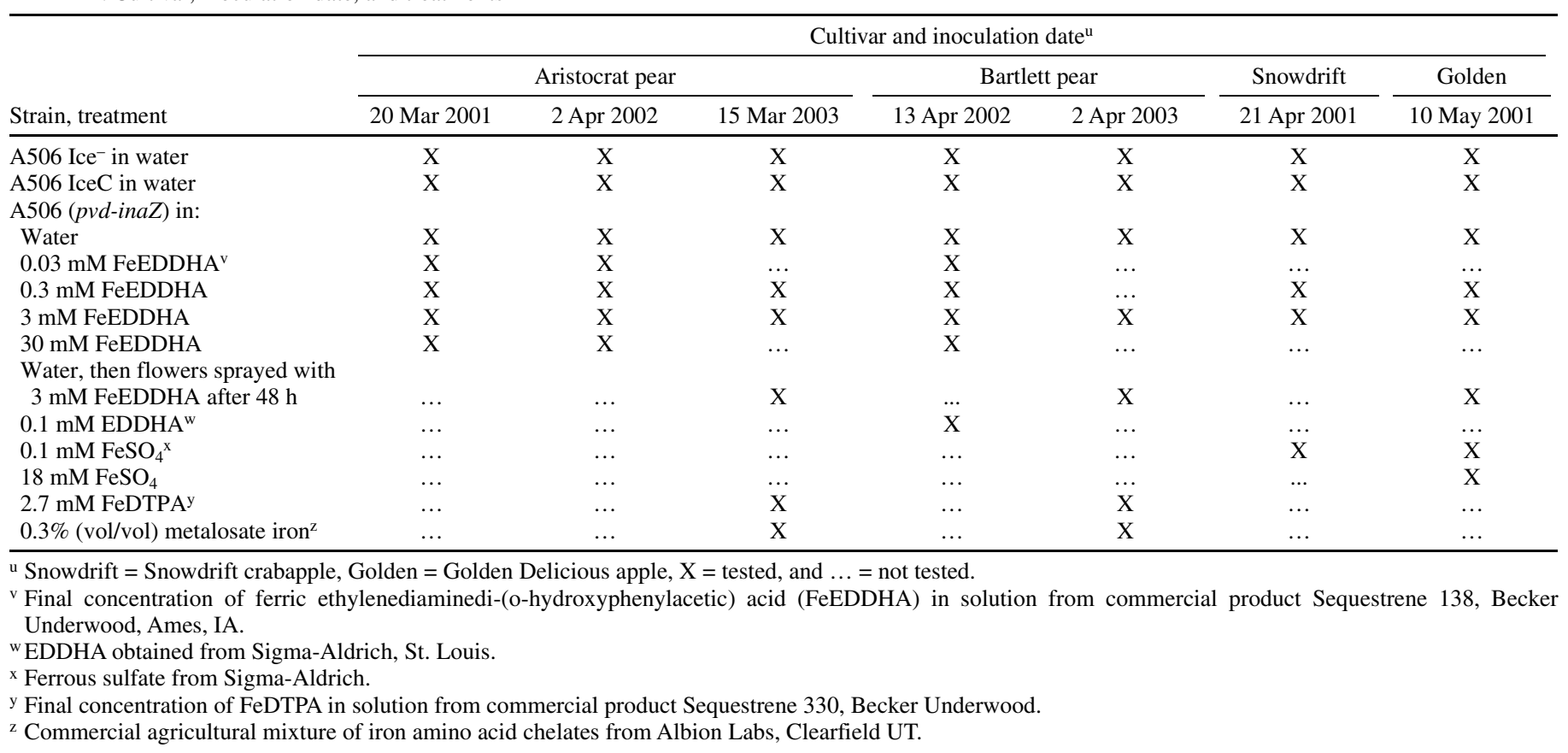


Ea153 (data not shown). On 925 medium amended with $\geq 0.1 \mathrm{mM}$ ferric citrate, A506 was not fluorescent under UV radiation and inhibited the growth of Ea153. Thus, similar concentrations of ferric citrate that suppressed pyoverdine-associated fluorescence of A506 on solidified 925 medium also induced antibiotic production and the inhibition of growth of Ea153.

In semi-quantitative assays conducted in 925 and RSM broth media, pyoverdine production by A506 was not detected in media containing 0.01 to $0.1 \mathrm{mM}$ ferric citrate (Fig. 1), and comparatively less pyoverdine was produced in 925 than in RSM. In contrast, antibiotic production by A506 grown in 925 medium increased with greater concentrations of ferric citrate in the medium, which confirmed the inverse relationship between pyoverdine production and antibiotic production by this bacterium (Fig. 1).

INA expressed by A506 (pvd-inaZ) in culture. After $24 \mathrm{~h}$ of growth in RSM, the density of A506 (pvd-inaZ) increased 2,000fold to $2 \times 10^{9} \mathrm{CFU} / \mathrm{ml}$; iron amendments to this medium did not affect the final cell density. The transcriptional activity of this construct was responsive to the concentration of iron in the growth medium with a change of five to six log units of activity occurring over a three-log-unit range of iron concentrations (Fig. 2). For both FeEDDHA and ferric citrate, the greatest rates of reduction of INA occurred as the iron concentration increased from 0.01 to $0.1 \mathrm{mM}$ of iron (Fig. 2).

Population size of A506 constructs applied to flowers in water. A506 ( $p v d$-inaZ), A506 $\mathrm{Ice}^{-}$, and A506 IceC were recovered in similar numbers from pear and apple flowers sampled over the time course of the experiment (Fig. 3; apple data not shown). In general, measured population sizes of the A506 constructs ranged from $10^{4}$ to $10^{6} \mathrm{CFU} /$ flower. ANOVA for mean $\log _{10} \mathrm{CFU}$ populations averaged over sampling times from 24 to $120 \mathrm{~h}$ postinoculation showed no significant differences $(P>0.05)$ among the constructs of A506 in all seven experiments (data not shown).

Ice nucleation activity of A506 constructs applied to flowers in water. As expected, INA for cells treated with A506 Ice was very low (near the detection limit of $1 \times 10^{-6} \log _{10}$ [ice nuclei/CFU]) on most colonized flowers (Fig. 4). In contrast, and also as expected, A506 IceC yielded high INA with values for $\log _{10}$ (ice nuclei/CFU) ranging from -0.2 to -2.0 over the seven experiments (Table 2; Fig. 4) The INA of A506 $\mathrm{Ice}^{-}$and A506

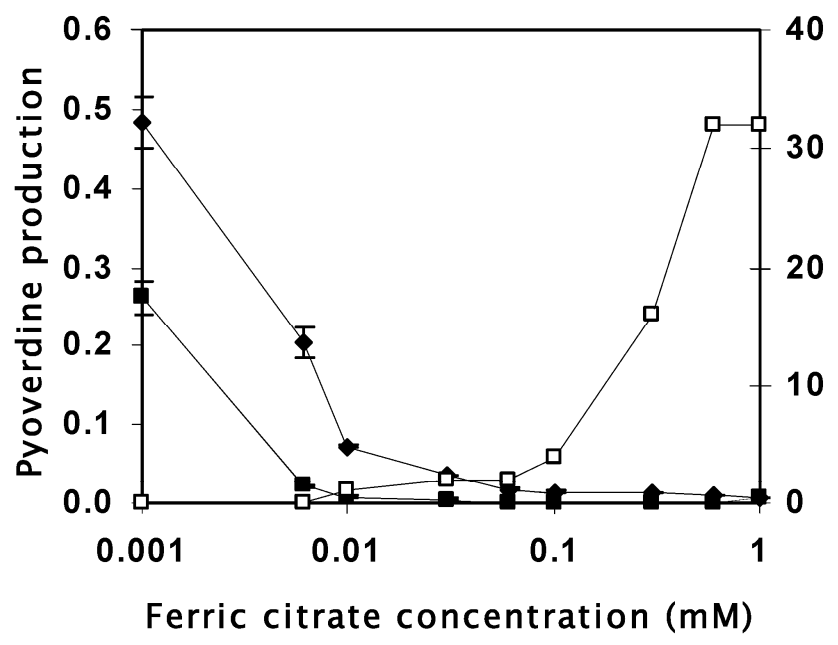

Fig. 1. Pyoverdine production of Pseudomonas fluorescens A506 after $72 \mathrm{~h}$ of incubation at $20^{\circ} \mathrm{C}$ in RSM medium ( $\bullet$ ) (2) and 925 medium (ष) (8) supplemented with ferric citrate at concentrations between 0.001 and $1 \mathrm{mM}$. Pyoverdine production was estimated from the absorbance at $405 \mathrm{~nm}\left(A_{405}\right)$ of the ferric-pyoverdine complex in culture media divided by $A_{600}$ measurement of cell density (13). Antibiotic production $(\square)$ of A506 in the 925 medium amended with ferric citrate is presented as the greatest dilution of culture media with detectable antibiotic activity against Erwinia amylovora. The values represent means of three replicate cultures and the vertical bars are \pm one standard error of the mean.
IceC were significantly different from each other at each time point in all experiments.

The inoculum suspensions and the flowers sampled immediately after inoculation with A506 ( $p v d$-inaZ) expressed low INA, indicating that the addition of ferric citrate to the culture media suppressed the $p v d$ promoter and production of InaZ in this construct. The values for $\log _{10}$ (ice nuclei/CFU) from initial flower samples treated with A506 ( $p v d$-inaZ) ranged from -5.4 to -4.3

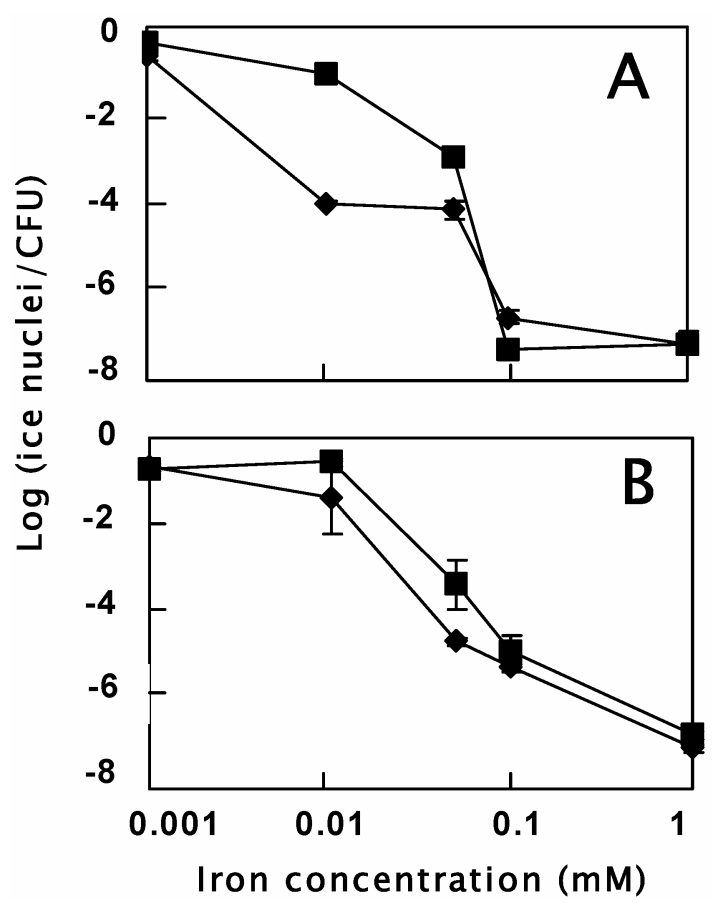

Fig. 2. Ice nucleation activity (log [ice nuclei/CFU]) of Pseudomonas fluorescens A506 (pvd-inaZ) ( $)$ and P. putida N1R $(\diamond)$ after $24 \mathrm{~h}$ of incubation in RSM medium (2) as influenced by concentration of $\mathbf{A}$, ferric citrate or $\mathbf{B}$, ferric ethylenediaminedi-(o-hydroxyphenylacetic) acid. Points are means of three replicate cultures; vertical bars drawn through points represent \pm one standard error of the mean.

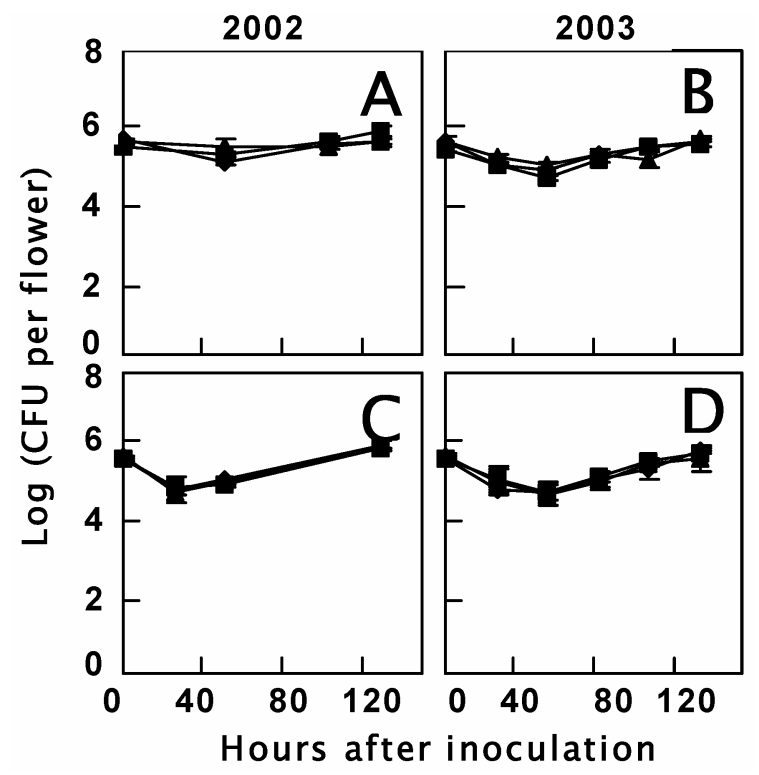

Fig. 3. Population size (log) of Pseudomonas fluorescens constructs A506 (pvd-inaZ) (ם), A506 IceC $(\bullet)$, or A506 Ice $^{-}(\mathbf{\Delta})$ on individual flowers in relation to hours after inoculation in suspensions of water. Panels represent experiments conducted on screenhouse-grown trees of $\mathbf{A}$, Aristocrat pear 2002, B, Aristocrat pear 2003, C, Bartlett pear 2002, and D, Bartlett pear 2003. Vertical bars drawn through points represent \pm one standard error of the mean. 
(Fig. 4), which was similar to INA of cells treated with A506 Ice ${ }^{-}$ in six of seven experiments (data not shown). By $48 \mathrm{~h}$ after inoculation, $\log _{10}$ (ice nuclei/CFU) for flowers treated with A506 ( $p v d$ inaZ) had increased to a range of values from -1.5 to -0.3 (Fig. 4 ), and this increase in activity was maintained over the time course of the experiments (Fig. 4).

Average INA for A506 IceC and A506 ( $p v d$-inaZ) did not differ significantly $(P \leq 0.05)$ in five of seven experiments (Table 2$)$. In all experiments, averages for both A506 IceC and A506 ( $p v d$ inaZ) were significantly larger $(P \leq 0.05)$ than those obtained for A506 Ice ${ }^{-}$(Table 2). For Aristocrat and Bartlett pear in 2003, the average INA response for A506 ( $p v d$-inaZ) was intermediate to the responses measured for A506 IceC and A506 Ice (Table 2). From analysis of pooled data, similar INA was observed for A506 IceC and A506 (pvd-inaZ) on apple and pear flowers but the INA of A506 Ice ${ }^{-}$from flowers was significantly $(P \leq 0.05)$ smaller (Table 2).

Effect of FeEDDHA on population size and INA of A506 IceC and A506 (pvd-inaZ). Populations of A506 (pvd-inaZ) mixed with FeEDDHA ranged from $10^{4}$ to $10^{6} \mathrm{CFU} /$ flower among the experiments (Fig. 5), similar to the measured population sizes of A506 ( $p v d$-inaZ) applied to flowers in water. In six of seven experiments, ANOVA of the population size of A506 ( $p v d$ inaZ) averaged from samples taken 24 to $120 \mathrm{~h}$ after inoculation revealed no significant effects $(P>0.05)$ of co-treatment with any tested concentration of FeEDDHA (Fig. 5).

In two preliminary experiments in 2000, $3 \mathrm{mM}$ FeEDDHA did not affect the INA of the construct A506 IceC on pear or crabapple flowers (data not shown), demonstrating that the presence of FeEDDHA did not interfere with measured INA. The INA of A506 ( $p v d$-inaZ) recovered from flowers was affected significantly $(P<0.05)$ by the concentration of FeEDDHA in the inoculum suspension. The INA of A506 ( $p v d$-inaZ) on flowers treated with $0.03 \mathrm{mM}$ FeEDDHA was similar to mixing the construct with water (Table 3). Mixing A506 (pvd-inaZ) with $0.3 \mathrm{mM}$ FeEDDHA significantly reduced the average INA of cells compared with treatment with water in three of six experiments (Table 3; Fig. 6A, B, and C). In all experiments, the INA of A506 ( $p v d$ inaZ) on flowers mixed in $3 \mathrm{mM}$ FeEDDHA was suppressed significantly $(P \leq 0.05)$ compared with treatment with this construct

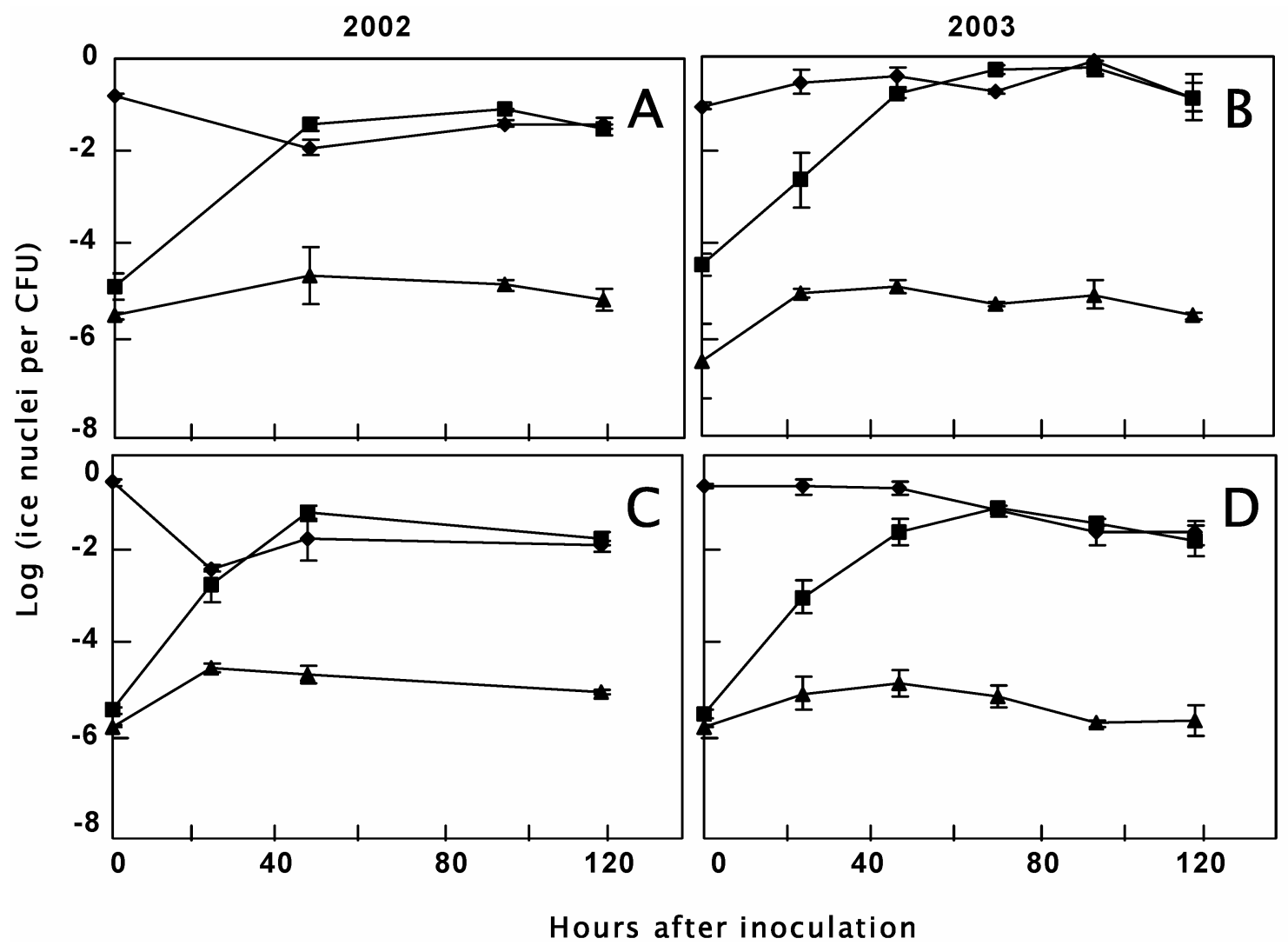

Fig. 4. Ice nucleation activity (log [ice nuclei/CFU]) of Pseudomonas fluorescens constructs A506 (pvd-inaZ) (₫), A506 IceC ( $\bullet)$, or A506 Ice ${ }^{-}(\boldsymbol{\Delta})$ on individual flowers in relation to hours after inoculation in suspensions of water. Panels represent experiments conducted on screenhouse-grown trees of A, Aristocrat pear 2002, B, Aristocrat pear 2003, C, Bartlett pear 2002, and D, Bartlett pear 2003. Vertical bars drawn through points represent \pm one standard error of the mean.

TABLE 2. $\log _{10}$ (ice nucleation activity/CFU) on flowers of pear and apple treated with constructs of Pseudomonas fluorescens A506 suspended in water ${ }^{2}$

\begin{tabular}{|c|c|c|c|c|c|c|c|c|}
\hline \multirow[b]{3}{*}{ A506 construct } & \multicolumn{7}{|c|}{ Year and cultivar } & \multirow[b]{3}{*}{ Pooled } \\
\hline & \multicolumn{3}{|c|}{2001} & \multicolumn{2}{|c|}{2002} & \multicolumn{2}{|c|}{2003} & \\
\hline & Snowdrift & Golden & Aristocrat pear & Aristocrat pear & Bartlett pear & Aristocrat pear & Bartlett pear & \\
\hline$p v d$-inaZ & $-1.4 \mathrm{a}$ & $-0.8 \mathrm{a}$ & $-0.2 \mathrm{a}$ & $-1.3 \mathrm{a}$ & $-1.9 \mathrm{a}$ & $-1.0 \mathrm{~b}$ & $-1.8 \mathrm{~b}$ & $-1.2 \mathrm{a}$ \\
\hline $\mathrm{Ice}^{-}$ & $-5.7 \mathrm{~b}$ & $-3.1 \mathrm{~b}$ & $-4.0 \mathrm{~b}$ & $-4.8 b$ & $-4.6 b$ & $-5.1 \mathrm{c}$ & $-5.2 \mathrm{c}$ & $-4.6 \mathrm{~b}$ \\
\hline
\end{tabular}

${ }^{\mathrm{z}}$ Ice nucleation activity was measured with the droplet freezing assay; CFU were estimated by dilution plating individual flowers onto a selective medium. Mean shown is the average of two to five flower samples taken 24 to $120 \mathrm{~h}$ after treatment. An aqueous suspension of constructs of A506 at $1 \times 10^{8} \mathrm{CFU} / \mathrm{ml}$ was sprayed onto flowers to near runoff. Snowdrift $=$ Snowdrift crabapple and Golden $=$ Golden Delicious apple. Means within a column followed by the same letter are not significantly different according to Fisher's protected least significant difference at $P=0.05$. 
in $0.3 \mathrm{mM}$ FeEDDHA or in water (Table 3; Fig. 6). Greater concentrations of FeEDDHA did not further suppress INA, because the average INA of A506 ( $p v d$-inaZ) on flowers suspended in $30 \mathrm{mM}$ FeEDDHA was similar to flowers treated with the construct in $3 \mathrm{mM}$ FeEDDHA (Table 3).

In two experiments in 2003, an overspray of $3 \mathrm{mM}$ FeEDDHA on flowers $48 \mathrm{~h}$ after inoculation with A506 (pvd-inaZ) suppressed INA compared with flowers treated with A506 ( $p v d$-inaZ) in water (Fig. 6B and D). For Bartlett pear in 2002, the additional control treatment A506 ( $p v d$-inaZ) mixed with $0.1 \mathrm{mM}$ EDDHA (nonferrated chelate) yielded responses similar to those observed for A506 ( $p v d$-inaZ) in water (Table 3).

Effect of additional agricultural iron sources on A506 (pvdinaZ). In 2003, mean population sizes of A506 ( $p v d$-inaZ) mixed with FeDTPA or metalosate-iron were not significantly different $(P>0.05)$ from those of A506 ( $p v d$-inaZ) mixed in water (data not shown). In 2001, mean population sizes of A506 ( $p v d$-inaZ)

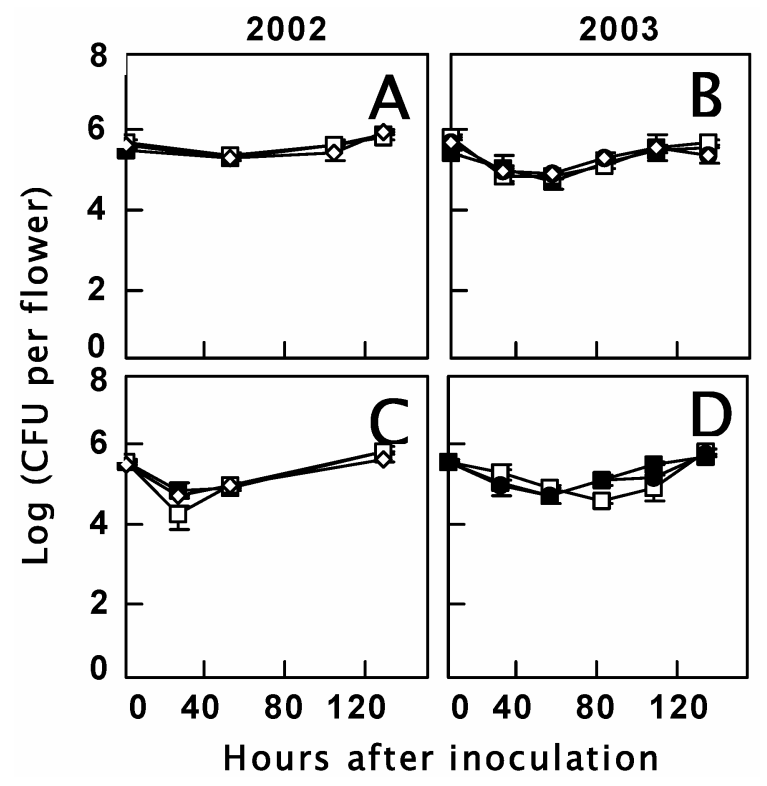

Fig. 5. Population size (log) of Pseudomonas fluorescens strain A506 (pvdinaZ) on individual flowers in relation to hours after inoculation in suspensions of water $(\mathbf{\square}), 0.3 \mathrm{mM}$ ferric ethylenediaminedi-(o-hydroxyphenylacetic) acid (FeEDDHA) ( $\diamond$, A to $\mathbf{C}$ only), $3 \mathrm{mM}$ FeEDDHA ( $\square$ ), or $3 \mathrm{mM}$ FeEDDHA at $48 \mathrm{~h}$ after inoculation $(\bullet, 2003$ only). Panels represent experiments conducted on screenhouse-grown trees of A, Aristocrat pear 2002, B, Aristocrat pear 2003, C, Bartlett pear 2002, and D, Bartlett pear 2003. Vertical bars drawn through points represent \pm one standard error of the mean. mixed with $0.1 \mathrm{mM} \mathrm{FeSO}_{4}$ on Golden Delicious apple were significantly smaller $(P<0.05)$ than when the construct was mixed in water; however, this treatment did not suppress populations of A506 ( $p v d$-inaZ) on crabapple (data not shown). Combining A506 (pvd-inaZ) with $18 \mathrm{mM} \mathrm{FeSO}_{4}$ in 2001 resulted in significantly smaller $(P<0.05)$ population sizes of A506 ( $p v d$ inaZ) of $\approx 3,000$-fold fewer cells when compared with the watertreated control (data not shown).

From 24 to $120 \mathrm{~h}$ after inoculation, the average INA of A506 ( $p v d$-inaZ) on treated flowers mixed with $\mathrm{FeSO}_{4}$, FeDTPA, or metalosate-iron ranged from -2.4 to -4.5 , which was significantly $(P<0.05)$ lower than the INA measured with A506 ( $p v d$-inaZ) on flowers in water (Table 3). Although 0.1 and $18 \mathrm{mM} \mathrm{FeSO}_{4}$ reduced INA compared with the water control, the level of suppression of activity was significantly less than that obtained from treatment with $3 \mathrm{mM}$ FeEDDHA (Table 3 ). The relative degree of suppression of INA with FeDTPA or metalosate-iron was statistically similar to the degree of suppression obtained with $3 \mathrm{mM}$ FeEDDHA (Table 3).

\section{DISCUSSION}

This study used an iron biosensor to examine the relative biological availability of iron to A506 ( $p v d$-inaZ) on surfaces of pear and apple flowers through the suppression or expression of an iron-regulated promoter at the transcriptional level. This question is of interest because A506, a biological control agent for fire blight disease of pear and apple flowers, produces an antibiotic inhibitory to the target pathogen when cultured on defined media that contain iron at concentrations of $\geq 0.1 \mathrm{mM}$ (25). Thus, whether or not iron is available to A506 on flower surfaces may potentially influence the effectiveness of the biocontrol interaction. To our knowledge, this is the first time that a biosensor has been used to guide the development of a disease control tactic for an agricultural crop. Based on the data collected in this study, field studies are ongoing to determine if the addition of iron to the floral habitat directly influences the quality of the biocontrol interaction.

The antibiotic of A506 has not been characterized, but it can be detected readily with bioassays conducted on chemically defined culture media. We confirmed that addition of $\geq 0.1 \mathrm{mM}$ ferric citrate to broth cultures or solidified media resulted in production of detectable concentrations of the antibiotic by A506. Like many fluorescent pseudomonads, A506 produces a pyoverdine siderophore on iron-deplete media, but not in media amended with $0.1 \mathrm{mM}$ ferric chloride. We consistently observed that concentrations of iron that suppressed pyoverdine production also stimu-

TABLE 3. $\log _{10}$ (ice nucleation activity/CFU) on flowers of pear and apple treated with Pseudomonas fluorescens A506 (pvd-inaZ) suspended in water or an iron solution ${ }^{y}$

\begin{tabular}{|c|c|c|c|c|c|c|c|c|}
\hline \multirow[b]{3}{*}{ Treatment $^{\mathrm{z}}$} & \multicolumn{7}{|c|}{ Year and cultivar } & \multirow[b]{3}{*}{ Pooled } \\
\hline & \multicolumn{3}{|c|}{2001} & \multicolumn{2}{|c|}{2002} & \multicolumn{2}{|c|}{2003} & \\
\hline & Snowdrift & Golden & Bartlett pear & Aristocrat pear & Bartlett pear & Aristocrat pear & Bartlett pear & \\
\hline Water & $-1.4 \mathrm{a}$ & $-0.8 \mathrm{a}$ & $-2.8 \mathrm{a}$ & $-1.3 \mathrm{a}$ & $-1.9 \mathrm{a}$ & $-1.0 \mathrm{a}$ & $-1.8 \mathrm{a}$ & $-1.4 \mathrm{a}$ \\
\hline $0.03 \mathrm{mM}$ FeEDDHA & $\ldots$ & $\ldots$ & $\ldots$ & $-1.2 \mathrm{a}$ & $-2.1 \mathrm{a}$ & $\ldots$ & $\ldots$ & $-1.3 \mathrm{a}$ \\
\hline 0.3 mM FeEDDHA & $-2.8 \mathrm{~b}$ & $-1.9 \mathrm{ab}$ & $-3.0 \mathrm{a}$ & $-1.4 \mathrm{a}$ & $-2.6 b$ & $-2.0 \mathrm{~b}$ & $\ldots$ & $-2.0 \mathrm{a}$ \\
\hline 3 mM FeEDDHA & $-4.1 c$ & $-5.0 \mathrm{e}$ & $-4.5 b$ & $-4.8 b$ & $-4.5 c$ & $-4.6 d$ & $-4.8 c$ & $-4.2 c$ \\
\hline 30 mM FeEDDHA & $\ldots$ & $\ldots$ & $\ldots$ & $-4.6 b$ & $-4.1 c$ & $\ldots$ & $\ldots$ & $-3.5 b c$ \\
\hline $0.1 \mathrm{mM}$ EDDHA & $\ldots$ & $\ldots$ & $\ldots$ & $\ldots$ & $-1.6 \mathrm{a}$ & $\ldots$ & $\ldots$ & $-1.6 \mathrm{a}$ \\
\hline $0.1 \mathrm{mM} \mathrm{FeSO}_{4}$ & $-2.4 \mathrm{~b}$ & $-3.5 \mathrm{~cd}$ & $\ldots$ & $\ldots$ & $\ldots$ & $\ldots$ & $\ldots$ & $-2.9 b$ \\
\hline $18 \mathrm{mM} \mathrm{FeSO}_{4}$ & $\ldots$ & $-3.0 \mathrm{bc}$ & $\ldots$ & $\ldots$ & $\ldots$ & $\ldots$ & $\ldots$ & $-3.0 \mathrm{~b}$ \\
\hline $2.7 \mathrm{mM}$ FeDTPA & $\ldots$ & $\ldots$ & $\ldots$ & $\ldots$ & $\ldots$ & $-3.6 c$ & $-4.2 b$ & $-3.9 c$ \\
\hline $0.3 \%$ (vol/vol) metalosate iron & $\ldots$ & $\ldots$ & $\ldots$ & $\ldots$ & $\ldots$ & $-3.6 c$ & $-4.5 \mathrm{bc}$ & $-4.0 \mathrm{c}$ \\
\hline
\end{tabular}

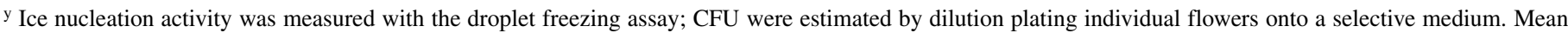
shown is the average of two to five flower samples taken 24 to $120 \mathrm{~h}$ after treatment. A506 (pvd-inaZ) at $1 \times 10^{8} \mathrm{CFU} / \mathrm{ml}$ was sprayed onto flowers to near runoff in water or an iron solution. Snowdrift $=$ Snowdrift crabapple and Golden = Golden Delicious apple. Means within a column followed by the same letter are not significantly different according to Fisher's protected least significant difference at $P=0.05 ; \ldots=$ not tested.

${ }^{\mathrm{z}} \mathrm{FeEDDHA}=$ ferric ethylenediaminedi-(o-hydroxyphenylacetic) acid. 
lated antibiosis of A506 (Fig. 1). Without information on the structure of the antibiotic of A506 or the biosynthetic genes, this inverse relationship between pyoverdine production and antibiosis should be considered correlative, not causative. Nonetheless, this correlation indicates that, if iron is present in a habitat at sufficient concentrations to suppress pyoverdine production, then adequate iron should be present to induce antibiosis by A506. Measuring the transcriptional activity of $p v d$-inaZ provides a tool to determine if iron is available in a habitat at concentrations adequate to suppress the iron-regulated promoter involved in pyoverdine production (15), which we construe may be adequate for stimulation of antibiosis.

Broth culture experiments confirmed that the transcriptional activity of $p v d$-inaZ in A506 was responsive to iron concentration. In RSM medium containing $\geq 0.1 \mathrm{mM}$ ferric citrate, transcriptional activity of $p v d$-inaZ in A506 was suppressed and pyoverdine was not detected in culture supernatants (Figs. 1 and 2). Loper and Lindow (15) also observed that iron-replete media that suppressed transcription of $p v d-i n a Z$ in Pseudomonas syringae and production of pyoverdine. P. putida N1R ( $p v d$-inaZ), whose transcriptional activity is known under varying concentrations of ferric citrate, was used as a comparative control (14). In addition, the population size of A506 ( $p v d$-inaZ) was similar to that of P. putida N1R ( $p v d$-inaZ) (Fig. 2). The transcriptional $p v d$ activity expressed by A506 ( $p v d$-inaZ) was similar to N1R ( $p v d$-inaZ) in response to ferric citrate or FeEDDHA at the concentrations tested. In the screenhouse, the amount of FeEDDHA (3 mM) required to suppress the transcriptional activity of the biosensor in A506 ( $p v d$-inaZ) was at least one log unit higher on flowers than in broth culture $(0.1 \mathrm{mM})$. This may be due, in part, to unique features of floral habitats occupied by A506 ( $p v d$-inaZ). We conclude that results of the influence of iron on transcriptional activity of $p v d$-inaZ in the broth culture experiments underestimated the con- centration of exogenous iron required to suppress transcription of pvd-inaZ in A506 on flowers.

After inoculation on flowers, population size determinations were made to compare relative reproductive fitness among constructs of A506 and to express ice nucleation frequency in terms of ice nuclei/CFU. With specific consideration to fitness, all three constructs (A506 ( $p v d$-inaZ), A506 $\mathrm{Ice}^{-}$, and A506 IceC) maintained populations sizes of $10^{4}$ to $10^{6} \mathrm{CFU} /$ flower (Fig. 3). There was no indication that a specific construct (A506 (pvd-inaZ), A506 Ice - and A506 IceC) was detrimental to the reproductive fitness of A506 on flowers. Similarly, P. syringae 31R1, P. putida $\mathrm{N} 1 \mathrm{R}$, and $P$. fluorescens Pf-5 containing $p v d$-inaZ, IceC, or Ice ${ }^{-}$ showed no apparent differences in epiphytic fitness among constructs in the rhizosphere or phyllosphere of several plants (1315,17).

The floral stigma represents a unique microbial habitat different from other aerial plant surfaces in that it offers an abundant, but transient, supply of nutrients (5). Leveau and Lindow (9) noted that bacterial epiphytes of bean leaves are commonly clustered near surface features where nutrient leakage would be likely occur (cracks, ruptures, stomates, and so on). Using a $p v d-g f p$ biosensor as well as $p v d$-inaZ in $P$. syringae, Joyner and Lindow (7) found that most $(\approx 90 \%)$ epiphytic cells on bean leaves sensed relatively abundant iron in the phyllosphere, with only a minority of cells experiencing limiting conditions. In contrast, we found that bioavailable iron is in limited supply on stigmatic surfaces of pear and apple flowers. This conclusion is supported by the observed shift in INA of A506 ( $p v d$-inaZ) from initially low levels (i.e., similar to A506 Ice ${ }^{-}$) to higher activities by $48 \mathrm{~h}$ after inoculation. In most of the experiments, these higher INAs approached those of A506 IceC. A major difference between bean leaves and rosaceous stigmas is that bacterial populations are typically a 1,000-fold greater (per gram of tissue basis) on the flo-

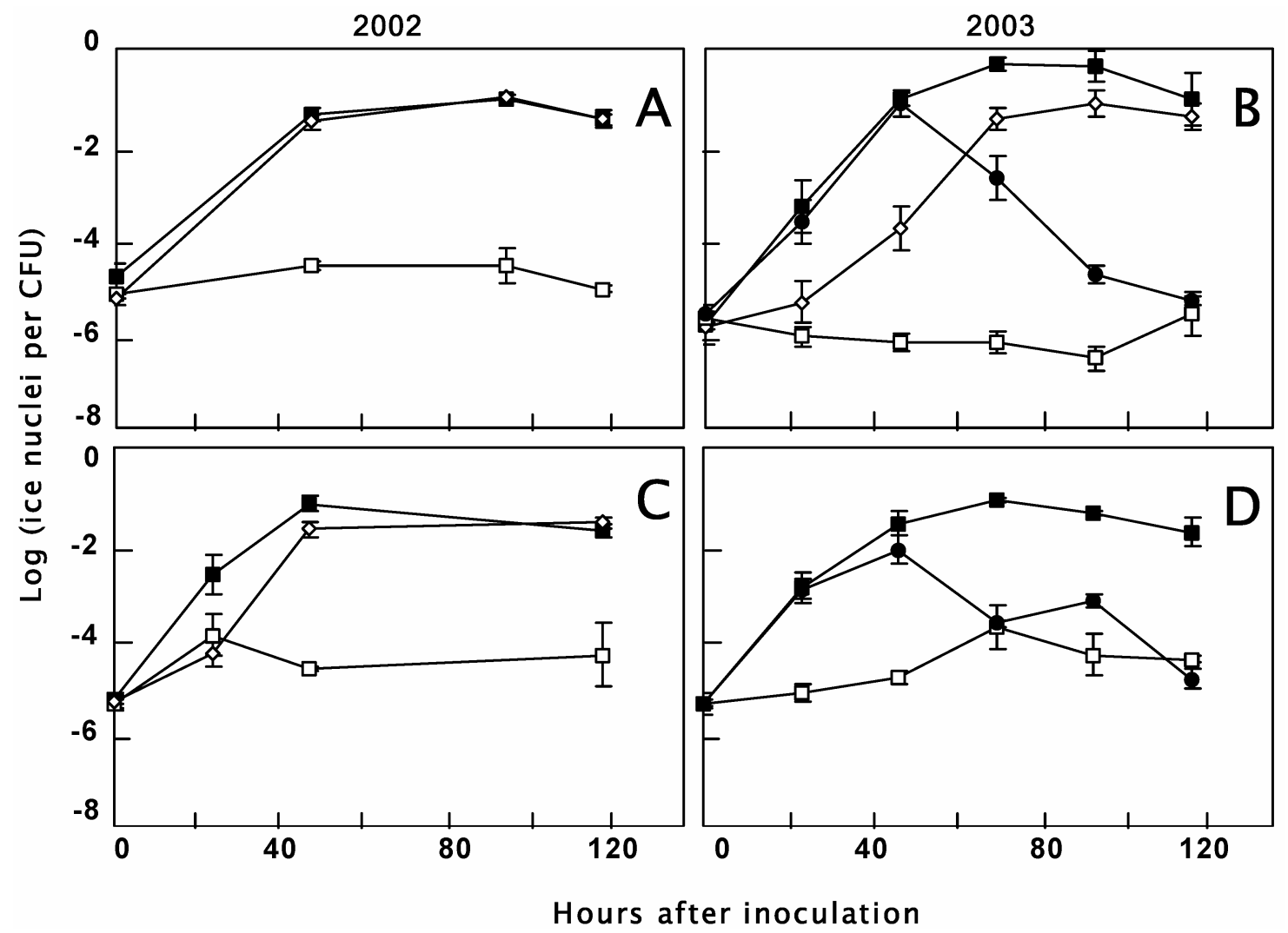

Fig. 6. Ice nucleation activity (log [ice nuclei/CFU]) of Pseudomonas fluorescens strain A506 (pvd-inaZ) on individual flowers in relation to hours after inoculation in suspensions of water ( $\square$ ), $0.3 \mathrm{mM}$ ferric ethylenediaminedi-(o-hydroxyphenylacetic) acid (FeEDDHA) ( $\diamond, \mathbf{A}$ to $\mathbf{C}$ only), $3 \mathrm{mM}$ FeEDDHA ( $\square$ ), or $3 \mathrm{mM}$ FeEDDHA at $48 \mathrm{~h}$ after inoculation $(\boldsymbol{\bullet}, 2003$ only). Panels represent experiments conducted on screenhouse-grown trees of A, Aristocrat pear 2002 , B, Aristocrat pear 2003, C, Bartlett pear 2002, and D, Bartlett pear 2003. Vertical bars drawn through points represent \pm one standard error of the mean. 
ral habitat (5). The high density of bacterial cells coupled with rapid growth that occurs on stigmatic tissues may result in high demand for iron and a rapid depletion of any existing iron sources. Marschner et al. (18) suggested that iron demand by bacteria should be highest when the population is growing rapidly and other nutrients (e.g., carbon) are readily available. Working with white lupine, this group observed that iron-limiting conditions to a pvd-inaZ construct of $P$. fluorescens Pf-5 were more strongly associated with the root tips where bacterial populations increase rapidly compared with older root surfaces. Similarly, Loper and Henkels (13) found that the rhizosphere of bean was iron limiting to Pf-5 (pvd-inaZ) in the 2 days following inoculation of this strain, but became less limiting as time progressed.

We evaluated several iron chelates and a ferrous compound for their ability to provide iron to A506 on floral surfaces. Most of our efforts focused on the use of the iron chelate FeEDDHA as a source of exogenous iron for A506. The addition of FeEDDHA to the inoculum had no significant effect on the measured population size of A506 ( $p v d$-inaZ) on flowers (Fig. 5). Significantly, FeEDDHA, when applied at concentrations of $\geq 3 \mathrm{mM}$, suppressed the shift from initially low to high frequencies of ice nucleation (Fig. 6). These data indicate the $3 \mathrm{mM}$ FeEDDHA treatment was at or somewhat above the minimal concentration of iron required to suppress the transcriptional activity of $p v d$-inaZ. In 2003, flowers sprayed with $3 \mathrm{mM}$ FeEDDHA delayed for $48 \mathrm{~h}$ after inoculation with A506 ( $p v d$-inaZ) in water also resulted in a significant decrease in INA (Fig. 6). We conclude that chelated forms of iron can be oversprayed on flowers colonized with A506 or mixed with the inoculum to increase iron bioavailability to the bacterium on the surface of pear or apple flowers.

Ferrous sulfate $\left(\mathrm{FeSO}_{4}\right)$, FeDTPA, and metalosate-iron were included to determine if other formulations of iron used commercially in agriculture could suppress INA of A506 ( $p v d$-inaZ) on flowers. The chelated forms of iron, applied at concentrations recommended by manufacturers for iron chlorosis, suppressed the INA of A506 ( $p v d$-inaZ) to a degree that was similar to that observed in the treatment amended with $3 \mathrm{mM}$ FeEDDHA (Table 3). $\mathrm{FeSO}_{4}$ reduced INA of A506 ( $p v d$-inaZ) compared with the water treatment, but not to the same degree as the iron chelates (Table $3)$. The high rate of $\mathrm{FeSO}_{4}(18 \mathrm{mM})$ which is recommended for alleviation of iron chlorosis caused a significant reduction in the recovered population size of A506 ( $p v d$-inaZ) on flowers when compared with treatments of FeEDDHA, EDDHA (chelate only), or water. Flowers treated with $18 \mathrm{mM} \mathrm{FeSO}_{4}$ appeared severely blackened, especially on petals and the tips of pistils. Severe phytotoxicity and marked reduction in populations of A506 ( $p v d$ inaZ) were not observed with $0.1 \mathrm{mM} \mathrm{FeSO}_{4}$ or with the other iron chelates at concentrations tested.

Compared with the other iron-containing compounds tested, FeEDDHA may show the most promise as an additive with A506 in field applications for fire blight suppression. Of the compounds evaluated, FeEDDHA has the highest affinity for ferric iron with a stability (iron binding) constant of 33.9 (3). From a microbial perspective, in iron-poor environments, siderophores are produced and secreted to sequester iron for growth (19). Consequently, the affinity by which iron is held by a chelate could allow iron to be collected by one organism's siderophore but not by the others. The stability constant for the pyoverdine produced by A506 is unknown, but it is likely to be similar to that for the pyoverdine of P. aeuruginosa, at 32.0 (21). Because FeEDDHA and pyoverdines have similar iron-stability constants, we expect that A506 ( $p v d$ inaZ) would utilize iron bound to this chelate. The observed shift in INA by A506 ( $p v d$-inaZ) in culture and in planta in the presence of FeEDDHA supports the expectation that A506 can utilize iron chelated by EDDHA. The siderophore of E. amylovora, desferrioxamine, which is a hydroxamate, has a considerably lower stability constant of 20.0 (4) and grows poorly in culture media amended with FeEDDHA. Thus, the high affinity of EDDHA for iron may provide more selectivity (i.e., iron available to A506 but not to E. amylovora) than FeDTPA or metalosate-iron (stability constants of 28.0 and estimated between 4.0 to 12.1 , respectively) (19).

In conclusion, the findings of this study provide evidence that a construct of $P$. fluorescens strain A506 containing the iron biosensor $p v d$-inaZ showed levels of INA consistent with the hypothesis that iron has limited bioavailability on surfaces of pear and apple flowers. Moreover, amendments of the iron chelate, FeEDDHA, at concentrations of $\geq 3 \mathrm{mM}$ suppressed INA, indicating that A506 ( $p v d$-inaZ) acquired sufficient iron to suppress this iron-regulated promoter. The implications of these results are that production of the iron-induced antibiotic of A506 is unlikely to occur in field applications without the addition of exogenous iron to flower surfaces. Applications of FeEDDHA, however, may modify the habitat on pear and apple flowers and, thus, may positively influence antibiotic production by A506 and fire blight suppression.

\section{ACKNOWLEDGMENTS}

This study was supported in part by grants from the United States Department of Agriculture Western Region Integrated Pest Management WRIPM-00R14 and the Winter Pear Control Committee. We thank Becker-Underwood for the gift of Sequestrene 138 and Sequestrene 330, Albion Laboratories for the gift of Metalosate Iron, and M. D. Henkels and other members of J. Loper's group for insightful comments and technical assistance.

\section{LITERATURE CITED}

1. Abdallah, M. A. 1991. Pyoverdins and pseudobactins. Pages 139-154 in: CRC Handbook of Microbial Iron Chelates. G. Winkelmann, ed. CRC Press, Boca Raton, FL.

2. Buyer, J. S., Sikora, L. J., and Chaney, R. L. 1989. A new growth medium for the study of siderophore-mediated interactions. Biol. Fertil. Soils 8:98-101.

3. Chaney, R. L. 1988. Plants can utilize iron from Fe- $N, N$ '-di-(2-hydroxybenzoyl)-ethylenediamine- $N, N^{\prime}$-diacetic acid, a ferric chelate with $10^{6}$ greater formation constant than Fe-EDDHA. J. Plant Nutr. 11: 1033-1050.

4. Expert, D., Dellagi, A., and Kachadourian, R. 2000. Iron and fire blight: Role in pathogenicity of desferrioxamine E, the main siderophore of Erwinia amylovora. Pages 179-195 in: Fire Blight, The Disease and Its Causative Agent, Erwinia amylovora. J. L. Vanneste, ed. CABI Publishing, New York.

5. Johnson, K. B., and Stockwell, V. O. 1998. Management of fire blight: A case study in microbial ecology. Annu. Rev. Phytopathol. 36:227-248.

6. Johnson, K. B., Stockwell, V. O., McLaughlin, R. J., Sugar, D., Loper, J. E., and Roberts, R. G. 1993. Effect of antagonistic bacteria on establishment of honey bee-dispersed Erwinia amylovora in pear flowers and on fire blight control. Phytopathology 83:995-1002.

7. Joyner, D. C., and Lindow, S. E. 2000. Heterogeneity of iron bioavailability on plants assessed with a whole-cell GFP-based bacterial biosensor. Microbiology 146:2435-2445.

8. Langley, R. A., and Kado, C. I. 1972. Studies on Agrobacterium tumefaciens. Conditions for mutagenesis by N-methyl- $\mathrm{N}^{\prime}$-nitro-N-nitrosoguanidine and relationships of A. tumefaciens to crown-gall tumor induction. Mutat. Res. 14:277-286.

9. Leveau, J. H. J., and Lindow, S. E. 2001. Appetite of an epiphyte: Quantitative monitoring of bacterial sugar consumption in the phyllosphere. Proc. Nat. Acad. Sci. USA 98:3446-3453.

10. Lindow, S. E. 1985. Integrated control and role of antibiosis in biological control of fire blight and frost injury. Pages 83-115 in: Biological Control on the Phylloplane. C. Windels and S. E. Lindow, eds. The American Phytopathological Society, St. Paul, MN.

11. Lindow, S. E. 1990. Bacterial ice nucleation activity. Pages 185-198 in: Methods in Phytobacteriology. S. Klement, K. Rudolg, and D. C. Sands, eds. Akademiai Kiado, Budapest.

12. Lindsay, W. L., and Schwab, A. P. 1982. The chemistry of iron in soils and its availability to plants. J. Plant Nutr. 5:821-840.

13. Loper, J. E., and Henkels, M. D. 1997. Availability of iron to Pseudomonas fluorescens in rhizosphere and bulk soil evaluated with an ice nucleation reporter gene. Appl. Environ. Microbiol. 63:99-105.

14. Loper, J. E., and Henkels, M. D. 1999. Utilization of heterologous siderophores enhances levels of iron available to Pseudomonas putida in the rhizosphere. Appl. Environ. Microbiol. 65:5357-5363. 
15. Loper, J. E., and Lindow, S. E. 1994. A biological sensor for iron available to bacteria in their habitats on plant surfaces. Appl. Environ. Microbiol. 60:1934-1941.

16. Loper, J. E., and Lindow, S. E. 2001. Reporter gene systems useful in evaluating in situ gene expression by soil- and plant-associated bacteria. Pages 627-637 in: Manual of Environmental Microbiology, 2nd ed. C. J. Hurst, G. R. Knudsen, M. J. McInerney, L. D. Stetzenbach, and M. V. Walter, eds. American Society for Microbiology Press, Washington DC

17. Marschner, P., and Crowley, D. E. 1997. Iron stress and pyoverdine production by fluorescent pseudomonad in the rhizosphere of white lupine (Lupinus albus L.) and barley (Hordeum vulgare L.). Appl. Environ. Microbiol. 63:277-281.

18. Marschner, P., Crowley, D. E., and Sattelmacher, B. 1997. Root colonization and iron nutritional status of Pseudomonas fluorescens in different plant species. Plant Soil 196:311-316.

19. Martell, A. E., and Smith, R. M. 1974. Critical Stability Constants, Vol. 1: Amino Acids. Plenum Press, New York.

20. Matzanke, B. F. 2000. Structures, coordination chemistry and functions of microbial iron chelates. Pages 15-64 in: CRC Handbook of Microbial Iron Chelates. G. Winkelmann, ed. CRC Press, Boca Raton, FL.

21. Meyer, J. M., and Abdallah, M. A. 1978. The fluorescent pigment of Pseudomonas fluorescens: Biosynthesis, purification, and physicochemical properties. J. Gen. Microbiol. 107:319-328.

22. Meyer, J. M., and Stintzi, A. 1998. Iron metabolism and siderophores in Pseudomonas and related species. Pages 201-239 in: Pseudomonas.
Biotechnology Handbooks, Vol. 10. T. C. Montie, ed. Plenum Press, New York.

23. Neilands, J. B. 1984. Siderophores of bacteria and fungi. Microbiol. Sci. 1:9-14.

24. Nuclo, R. L., Johnson, K. B., Stockwell, V. O., and Sugar, D. 1998. Secondary colonization of pear flowers by two bacterial antagonists of the fire blight pathogen. Plant Dis. 82:661-668.

25. Stockwell, V. O., Johnson, K. B., and Loper, J. E. 2001. Enhancement of biocontrol of fire blight with an iron chelate. (Abstr.) Phytopathology 91(suppl.):S86.

26. Stockwell, V. O., Johnson, K. B., and Loper, J. E. 2002. Biological control of fire blight: Understanding interactions among introduced and indigenous microbial communities. Pages 225-239 in: Phyllosphere Microbiology. S. E. Lindow, E. I. Hecht-Poinar, and V. J. Elliott, eds. The American Phytopathological Society, St. Paul, MN

27. Thomson, S. V. 1986. The role of the stigma in fire blight infections. Phytopathology 76:476-482.

28. Vali, G. 1989. Principles of ice nucleation. Pages 1-28 in: Biological Ice Nucleation and Its Applications. R. E. Lee, Jr., G. J. Warren, and L. V. Gusta, eds. The American Phytopathological Society, St. Paul, MN.

29. Wilson, M., Epton, H. A. S., and Sigee, D. C. 1989. Erwinia amylovora infection of hawthorn flower II. The stigma. J. Phytopathol. 127:15-28.

30. Wilson, M., and Lindow, S. E. 1993. Interactions between the biological control agent Pseudomonas fluorescens strain A506 and Erwinia amylovora in pear flowers. Phytopathology 83:117-123. 